\section{RICYDE. Revista Internacional de Ciencias del Deporte} doi: $10.5232 /$ ricyde

Rev. int. cienc. deporte

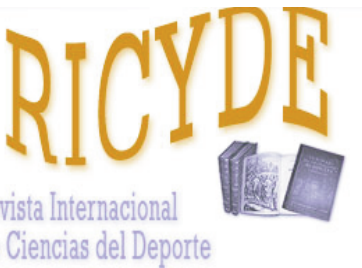

RICYDE. Revista Internacional de Ciencias del Deporte VOLUME XIV - YEAR XIV

Pages:124-135 ISSN:1885-3137

Issue: 52 - April - 2018

\title{
Kinematic analysis of rugby lineout throws in the Six Nations Tournament Análisis cinemático de los saques de lateral en el Torneo de Rugby del Seis Naciones
}

\author{
Ignacio Martín1, Pablo Mira1, José María Salinas ${ }^{1}$, Luis Vaz ${ }^{2}$ \& David Carreras ${ }^{3}$
}

1. Universidad de Granada. Spain

2. University of Trás-os-Montes e Alto Douro, Vila Real. Portugal

3. Universidad de Lleida. Spain

\begin{abstract}
This study examines 126 successful, six- or seven-man lineouts of the 2013 Six Nations Tournament. Data were extracted from footage of the competition to calculate kinematic variables along with jumper position. Through cluster analysis, six types of throw were identified according to distance and velocity: short-fast, short-slow, medium short-fast, medium short-slow, medium long and long. Significant differences were detected in all the variables examined depending on the throw category (throw distance $\mathrm{P}<0.001$; Partial eta square $\eta 2=0.932$, height $P=0.032 ; \eta 2=0.096$, flight time $P<0.001 ; \eta 2=0.789$, starting angle $P<0.001$; $\eta 2=0.502$, initial velocity $\mathrm{P}<0.001 ; \eta 2=0.767$ and jumper position $\mathrm{P}<0.001 ; \eta 2=0.641$ ). In the discriminant analysis, all variables except jumper position were able to correctly classify $100 \%$ of the throws. In addition, we differentiated the six participating teams, finding significant differences in throw height (Scotland vs England difference means $d=0.32 \mathrm{~m}$, Ireland $d=0.36 \mathrm{~m}$ or France $\mathrm{d}=0.37 \mathrm{~m}$ ), flight time (Italy vs England $\mathrm{d}=0.34 \mathrm{~s}$ or Ireland $\mathrm{d}=0.33 \mathrm{~s}$ ) and angle (Italy vs England $\mathrm{d}=9.72^{\circ}$ or Ireland $\mathrm{d}=8.49^{\circ}$ and Scotland vs England $d=8.27^{\circ}$ or Ireland $\mathrm{d}=7.04^{\circ}$ ). Our findings have implications for training and team analysis (own and rival) and also provide direction for future investigations.
\end{abstract}

Key words: Rugby Union; video analysis; differences by teams.

\section{Resumen}

El presente estudio ha investigado 126 saques de lateral ganados con seis o siete jugadores en el alineamiento del torneo de las Seis Naciones de 2013 La observación se ha realizado a partir del estudio de los videos, por lo que los datos están extraídos en competición real. Un análisis cluster nos ha permitido establecer seis tipos de lanzamientos en función de la distancia y la velocidad: cortos-rápidos, cortos-lentos, mediocortos-rápidos, mediocortos-lentos, mediolargos y largos. Hemos encontrado diferencias significativas en todas las variables estudiadas en función de los tipos de lanzamiento (distancia del lanzamiento $\mathrm{P}<0.001 ; \eta 2=0.932$, altura $\mathrm{P}=0.032 ; \mathrm{\eta} 2=0.096$, tiempo de vuelo $\mathrm{P}<0.001 ; \eta 2=0.789$, ángulo de salida $\mathrm{P}<0.001 ; \eta 2=0.502$, velocidad inicial $\mathrm{P}<0.001 ; \eta 2=0.767$ y posición del saltador $\mathrm{P}<0.001 ; \eta 2=0.641)$. El análisis discriminante incluyó todas las variables excepto la posición del saltador, clasificando correctamente el $100 \%$ de los casos. Además, hemos diferenciado a los seis equipos participantes encontrando diferencias significativas en altura (entre Escocia con Inglaterra $\mathrm{d}=0.32 \mathrm{~m}$, Irlanda $\mathrm{d}=0.36 \mathrm{~m}$ y Francia $\mathrm{d}=0.37 \mathrm{~m}$ ), tiempo de vuelo (entre Italia con Inglaterra $\mathrm{d}=0.34 \mathrm{~s}$ e Irlanda $\mathrm{d}=0.33 \mathrm{~s}$ ) y ángulo de salida (entre Italia con Inglaterra $d=9.72^{\circ}$ e Irlanda $d=8.49^{\circ}$ y de Escocia con Inglaterra $d=8.270$ e Irlanda $\left.\mathrm{d}=7.04^{\circ}\right)$. Del presente trabajo se derivan implicaciones para el entrenamiento, el análisis del equipo propio y del rival y para futuras investigaciones en los saques de lateral.

Palabras Clave: Rugby Union; análisis de video; diferencias por equipos.

Correspondence/correspondencia: Ignacio Martín

Departamento de Metodología de las Ciencias del Comportamiento. Universidad de Granada. Spain Email: imartin@ugr.es 
Martín, I.; Mira, P.; Salinas, J. S.; Vaz, L., \& Carreras, D. (2018). Kinematic analysis of rugby lineout throws in the Six Nations Tournament. RICYDE. Revista internacional de ciencias del deporte, 52(14), 124-135. https://doi.org/10.5232/ricyde2018.05203

\section{Introduction}

$\mathrm{T}$ he lineout is one of the means of restarting play that is most often used in a rugby match. In the 2013 Six Nations Tournament, a mean of 25 lineouts were disputed per match and $84 \%$ of all lineouts were won by the throwing team. It is also known that the stage in the game following the lineout is when $30 \%$ of all tries occur (International Rugby Board, 2013a).

According to the rules (International Rugby Board, 2013b) a lineout is used to restart the match when the ball touches the ground or something/someone out of the field of play. The player taking the lineout (thrower) throws the ball from outside the field to the middle of two lines of players (one for each team) positioned between the $5 \mathrm{~m}$ and $15 \mathrm{~m}$ lines parallel to the side line. Possession of the ball is contested between both lines and two team mates, one in front and one behind, can help elevate a jumper. The lineout throw is executed as preferred by the thrower in terms of speed, ball flight time, and starting angle and is conquered at different heights and distances by one of the players in the lineout.

Despite the important role played by lineouts among other aspects of the game, few studies have focused on this manoeuvre (Martín, Olmo, Chirosa, Carreras, \& Solá 2013; Villarejo, Palao, \& Ortega, 2010). Some game analysis studies have addressed lineouts among many other variables. Jones, Mellalieu, and James (2004) assessed in 20 professional team matches the capacity of 22 team execution indices to discriminate between winning or losing teams. These authors found that only the percentage of possessions won from the throwing team and percentage of tries scored from the total emerged as significant predictors of the winning team. In a later study, Ortega, Villarejo, and Palao (2009) examined 58 Six Nation matches over the seasons 2003 to 2006. Once again, one of the results highlighted the importance of lineout wins given that significantly fewer lineouts were lost by winning teams $(2.18 \pm 1.61)$ than losing teams $(3.38 \pm 2.11)$. However, Vaz, Van Rooyen, and Sampaio (2010), in a large sample of 120 International Rugby Board (IRB) and 204 Super 12 matches from 2003 to 2006, observed no differences between winners and losers according to lineout outcomes.

Studies that have specifically addressed lineouts have only examined the biomechanical characteristics of the thrower. Sayers (2004) addressed this aspect of the thrower for three throw distances $(6,10$ and $15 \mathrm{~m})$. For longer distances (over $10 \mathrm{~m})$ the greater participation of the lower limbs was required over the upper limbs whose contribution remained constant for all distances. Griffiths and Hughes (2005) analyzed similar throw heights for three distances $(5,10$ and $15 \mathrm{~m})$ and detected differences in the throws in initial ball velocity and angle velocities of the elbow, shoulder, knees and ankles of the player taking the lineout. Trewartha, Casanova, and Wilson (2008) characterized the throwing technique at different distances (6, 10,12 and $14 \mathrm{~m}$ ) for different trajectories (straight or curved, only up to $12 \mathrm{~m}$ ). These authors observed that the most elite thrower showed greater accuracy at any distance and peak joint angle velocities of both upper and lower limbs were synchronized, the participation of the lower extremities being greater for the longer throwing distances. In a more recent study by Sayers (2011), the relationship between throwing precision and characteristics and possible changes in these at longer throwing distances $(6,10,15 \mathrm{~m})$ were examined in three elite players. According to results, significant differences were produced in the key stages of the throw though high-level players shared several characteristics. However, the variables examined (trunk flexion at the end of the throw and elbow flexion) remained constant across the different throwing distances. 
Martín, I.; Mira, P.; Salinas, J. S.; Vaz, L., \& Carreras, D. (2018). Kinematic analysis of rugby lineout throws in the Six Nations Tournament. RICYDE. Revista internacional de ciencias del deporte, 52(14), 124-135.

https://doi.org/10.5232/ricyde2018.05203

In a virtual reality study by Croft, Chong, and Wilson (2011), thrower biomechanics was assessed in 8 elite rugby players in relation to throwing accuracy. Participants undertook at least 24 throws in different conditions of distance: short, medium and long. The factors associated with accurate throwing were elbow separation, front foot step, trunk flexion, and follow through.

Although these studies have centred on the biomechanical analysis of the thrower taking the lineout, there is no scientific evidence to support that the distances, angles, velocities or heights tested in these investigations are actually produced in high-level rugby matches. Lipscombe (2009) in his book about the physics of rugby undertakes a theoretical analysis of the lineout throw. This author considered that for a ball leaving the hands of the thrower at a height of two metres and caught by a player at a height of five metres, if the ball is intercepted $6 \mathrm{~m}$ from the side line, the throw angle will be $43^{\circ}$ and velocity $11 \mathrm{~m} \cdot \mathrm{s}^{-1}$, for an interception distance of $8 \mathrm{~m}$, this angle will be $35^{\circ}$ and velocity $13 \mathrm{~m} \cdot \mathrm{s}^{-1}$ and for a distance of $10 \mathrm{~m}$, these figures will be $35^{\circ}$ and $15 \mathrm{~m} \cdot \mathrm{s}^{-1}$ respectively. However, there is no empirical support for these data.

Thus, although investigations have examined the characteristics of lineout throws or of thrower biomechanics in an effort to improve throw accuracy, as far as we are aware, no kinematic data exist for these throws in high-level matches. The present study was designed to describe the kinematic features of lineout throws (starting angle, initial velocity, flight time, distance and height) along with jumper position in high-level competition matches. A further aim was to define different throw types according to these variables so that we could compare the characteristics of throws in the participating teams of the Six Nations championship.

\section{Methods}

\section{Sample}

In the 2013 Six Nations Tournament, 377 lineouts were taken in its 15 matches. The minimum and maximum numbers of lineouts played per match were 18 and 31 respectively. After excluding quick throws and lineouts that were not adequately video recorded, we selected all six- and seven-men lineouts in which possession was won by the throwing team in order to only examine successful throws. The final study sample consisted of 126 of such lineouts. Video footage of all 15 matches was contrasted with the statistics provided by the championship's official website (http://www.rbs6nations.com). The investigation was approved by the Ethics Committee of the University of Granada ( $\left.n^{\circ} 111 / \mathrm{CEIH} / 2015\right)$.

\section{Instrumentation}

All lineout variables were determined using the Kinovea 0.8 .15 package on video recordings previously treated with Vegas Pro 12.0. software. The data were cleaned and analyzed using Excel (Microsoft Corp., 2010) and IBM SPSS 21 (IBM Corp., 2012).

Design

Although the variables examined were kinematic, jumper position was also included to characterize the different throw types. The following are the definitions used for each variable determined:

- Distance (d): horizontal distance in $m$ traced by the ball from the side line to the perpendicular on the field at the point where the lineout player from the throwing team captures or palms the ball. 
Martín, I.; Mira, P.; Salinas, J. S.; Vaz, L., \& Carreras, D. (2018). Kinematic analysis of rugby lineout throws in the Six Nations Tournament. RICYDE. Revista internacional de ciencias del deporte, 52(14), 124-135. https://doi.org/10.5232/ricyde2018.05203

- Height (h): vertical distance in $\mathrm{m}$ from the ground to the perpendicular on the field at the point where the lineout player from the throwing team captures or palms the ball.

- Flight time $(\mathrm{t})$ : time in $\mathrm{s}$ from when the ball leaves the thrower's hands to the time the ball is touched by the lineout player.

- Angle $(\Theta)$ : angle in ${ }^{\circ}$ between the ball and plane of the field as it leaves the thrower's hands.

- Velocity (v): initial velocity in $\mathrm{m} \cdot \mathrm{s}^{-1}$ of the ball when it leaves the thrower's hands.

- Jumper position (jp): position occupied (1-7) by the lineout player from the throwing team who captures or palms the ball.

\section{Procedure}

A preliminary observational template was prepared for the six variables following the recommendations of Haynes, Richard, and Kubany (1995). To validate the observational system, we constructed a questionnaire with a Likert scale of 1 to 5 using Google Drive to obtain information from a group of seven experts on the pertinence and clarity of each variable defined and of the definitions provided. An open item was included for comments. These experts were renowned national rugby coaches. Mean scores \pm standard deviations obtained were $3.67 \pm 0.35$ for pertinence and $3.83 \pm 0.38$ for clarity.

Once the observational system had been validated, we analyzed the 126 Six Nations lineouts fulfilling the inclusion criteria based on footage from the HD transmission of the matches by the BBC. To determine each variable, the Kinovea programme was used. Initially, we calculated the factors height from the ground $\left(\mathrm{h}_{\mathrm{g}}\right)$, distance $(\mathrm{d})$ from the side line to the point where the ball was possessed and ball flight time ( $\mathrm{t}$ ). Next, we calculated the height at which the ball left the thrower's hands $\left(h_{h}\right)$ so that we could measure the difference in height $(h)$ between the point of throwing and point of possession of the ball. Finally, the variables angle $(\Theta)$ and initial velocity (v) were estimated from equations for a parabolic throw:

$$
\begin{gathered}
d=v \cdot \cos \theta \cdot t \\
a=v \cdot \sin \theta \cdot t-\frac{g \cdot t^{2}}{2}
\end{gathered}
$$

Using these equations, $\Theta$ and $v$ were calculated as:

$$
\begin{gathered}
\theta=\operatorname{arctg} \frac{a+\frac{g \cdot t^{2}}{2}}{d} \\
v=\frac{d}{\cos \theta \cdot t}
\end{gathered}
$$

Statistical Analysis

An overall descriptive analysis and bivariate correlations were conducted for each variable. This was followed by a hierarchical cluster analysis of the variables distance and velocity to create groups of lineouts according to throw type. The Ward method was used for clustering and the squared Euclidean distance method as a measure of similarity (Hair, Anderson, Tatham, \& Black, 1999). Analysis of variance was performed including all the variables examined as dependent variables and each of the clusters as factors. Bonferroni and Tuckey comparisons were conducted among the clusters. In addition, the contribution of each variable to predict each of the six clusters obtained was used as the criterion variable in a discriminant analysis. Finally, variables were compared across the six nations' teams through descriptive analysis and ANOVA. 
Martín, I.; Mira, P.; Salinas, J. S.; Vaz, L., \& Carreras, D. (2018). Kinematic analysis of rugby lineout throws in the Six Nations Tournament. RICYDE. Revista internacional de ciencias del deporte, 52(14), 124-135.

\section{Results}

We first analyzed the variables determined in the 126 lineouts finally included in the study (see Table 1) and correlations among these variables (see Table 2).

Table 1. Minimum, maximum, means, standard deviations and 95\% confidence intervals for the variables determined in the 126 lineouts examined.

\begin{tabular}{cccccc}
\hline & Min & Max & Mean & SD & $\mathbf{9 5 \%}$ CI \\
\hline $\mathbf{d}(\mathbf{m})$ & 5.00 & 15.00 & 9.39 & 3.13 & $8.83-9.94$ \\
$\mathbf{h}(\mathbf{m})$ & 2.70 & 4.13 & 3.60 & .32 & $3.55-3.66$ \\
$\mathbf{t}(\mathbf{s})$ & .36 & 1.55 & .96 & .30 & $0.90-1.01$ \\
$\mathbf{\Theta}\left({ }^{\circ}\right)$ & 18.10 & 51.84 & 33.26 & 7.26 & $31.98-34.54$ \\
$\mathbf{v}\left(\mathbf{m} \cdot \mathbf{s}^{-1}\right)$ & 8.79 & 14.97 & 11.91 & 1.51 & $11.64-12.17$ \\
$\mathbf{j p}$ & 2 & 6 & 3.66 & 1.41 & $3.41-3.91$ \\
\hline
\end{tabular}

Abbreviations: $\mathrm{d}=$ throw distance; $\mathrm{h}=$ height; $\mathrm{t}=$ flight time; $\mathrm{\Theta}=$ starting angle; $\mathrm{v}=$ initial velocity; jp= jumper position

Table 2. Bivariate correlations and 95\% confidence intervals among all the kinematic variables determined.

\begin{tabular}{|c|c|c|c|c|c|}
\hline & $\mathbf{h}$ & $\mathbf{t}$ & $\boldsymbol{\theta}$ & $\mathbf{v}$ & jp \\
\hline \multirow{2}{*}{ d (m) } & -.084 & $.844^{* *}$ & $.229^{* *}$ & $.588^{* *}$ & $.839^{* *}$ \\
\hline & $\begin{array}{lll}-.260 & .092\end{array}$ & $.785 \quad .888$ & $.056 \quad .388$ & .692. & $.778 \quad .884$ \\
\hline \multirow{2}{*}{$\mathbf{h}(\mathbf{m})$} & & .064 & $.403^{* *}$ & -.133 & .052 \\
\hline & & $\begin{array}{lll}-.110 .236\end{array}$ & $245 \quad .540$ & $\begin{array}{lll}-.300 & .043\end{array}$ & $-.120 \quad .225$ \\
\hline \multirow{2}{*}{$t(s)$} & & & $.694^{* *}$ & .126 & $.751^{* *}$ \\
\hline & & & $.591 \quad .775$ & $\begin{array}{ll}-.050 & .294\end{array}$ & .663 .818 \\
\hline \multirow{2}{*}{$\theta\left({ }^{\circ}\right)$} & & & & $-.516^{* *}$ & $.282^{* *}$ \\
\hline & & & & $\begin{array}{lll}-.630 & -.370\end{array}$ & .113 .435 \\
\hline \multirow{2}{*}{$v\left(m \cdot s^{-1}\right)$} & & & & & $.427^{* *}$ \\
\hline & & & & & $.272 \quad .560$ \\
\hline
\end{tabular}

Abbreviations: $d=$ throw distance; $h=$ height; $t=$ flight time; $\Theta=$ starting angle; $v=$ initial velocity; jp= jumper position

\section{Types of throw}

Following the descriptive analysis, we performed the cluster analysis. Given the high correlation between some of the variables examined along with the fact that some were algorithmically related in the equations provided, we identified clusters based only on the variables distance and velocity (see Figure 1).

These were selected to define comprehensible classes such as short-quick throws or medium short-slow throws. These variables also showed good behaviour at classifying the different lineouts.

Once we had selected these two variables, the hierarchical cluster analysis provided different solutions for the number of clusters. The resulting dendogram (Figure 1) using the Ward Method has provided us with solutions for two clusters ( short and long), three (short, medium- short and medium- long), four (short, medium- short, medium- long and long), or six clusters ( short-fast, short-slow, medium short-fast, medium short-slow, medium-long and long). On the other hand, after performing an analysis with NbClust software (Charrad, Ghazzali, Boiteau, Niknafs, \& Charrad, 2014), an R package for determining the relevant 
Martín, I.; Mira, P.; Salinas, J. S.; Vaz, L., \& Carreras, D. (2018). Kinematic analysis of rugby lineout throws in the Six Nations Tournament. RICYDE. Revista internacional de ciencias del deporte, 52(14), 124-135.

number of clusters in a data set, we obtained as a more suitable solution two clusters, although some indices showed other possible solutions such as those indicated in the dendogram. Finally, we choose the solution of selecting six clusters (Figure 2) which is the classification that is more similar to that used by researchers and trainers in the scope of SL and because it was also selected by Rubin, Cindex, Gamma and Gplus in NbClust.

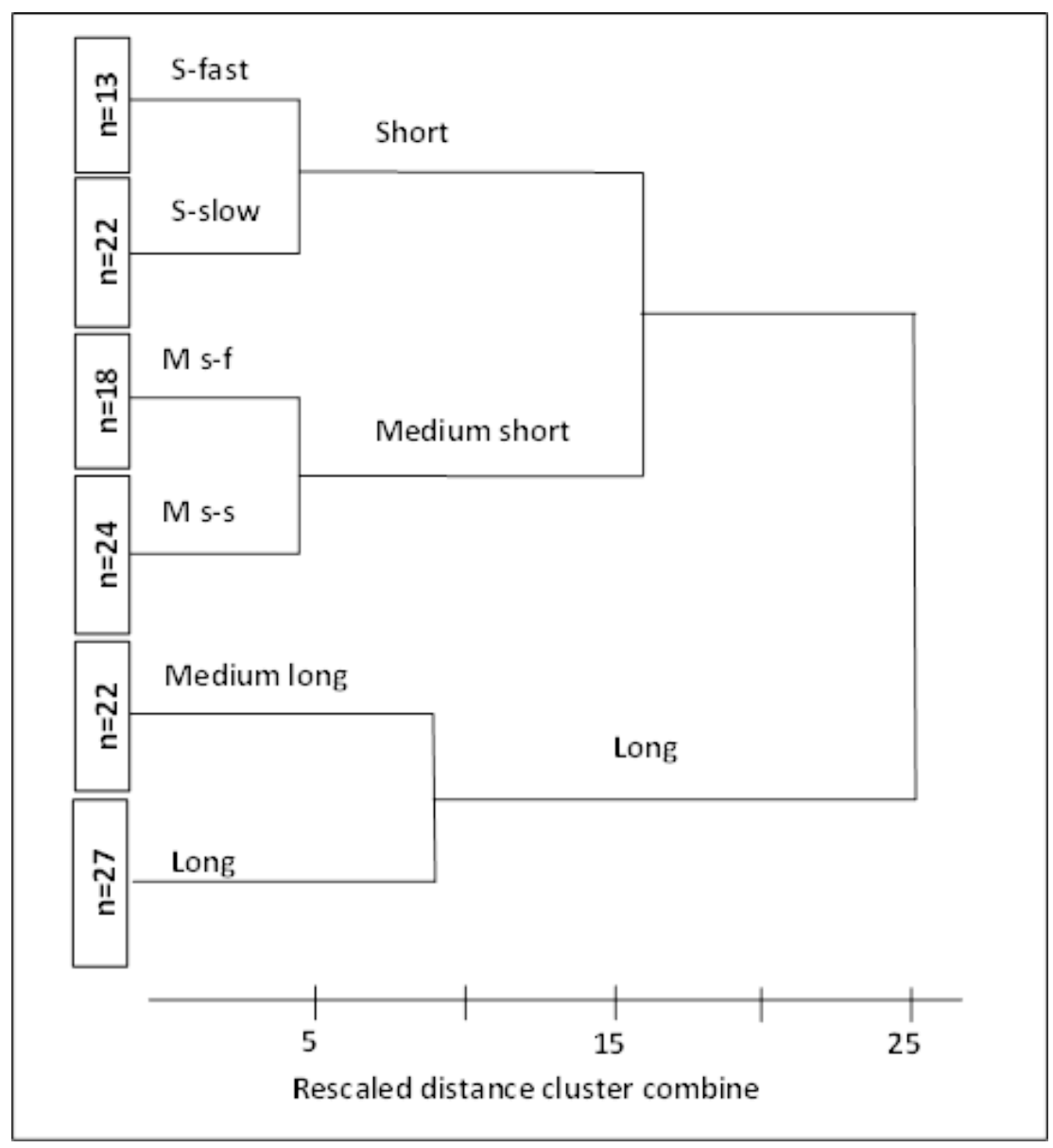

Figure 1. Dendogram using Ward's method 
Martín, I.; Mira, P.; Salinas, J. S.; Vaz, L., \& Carreras, D. (2018). Kinematic analysis of rugby lineout throws in the Six Nations Tournament. RICYDE. Revista internacional de ciencias del deporte, 52(14), 124-135.

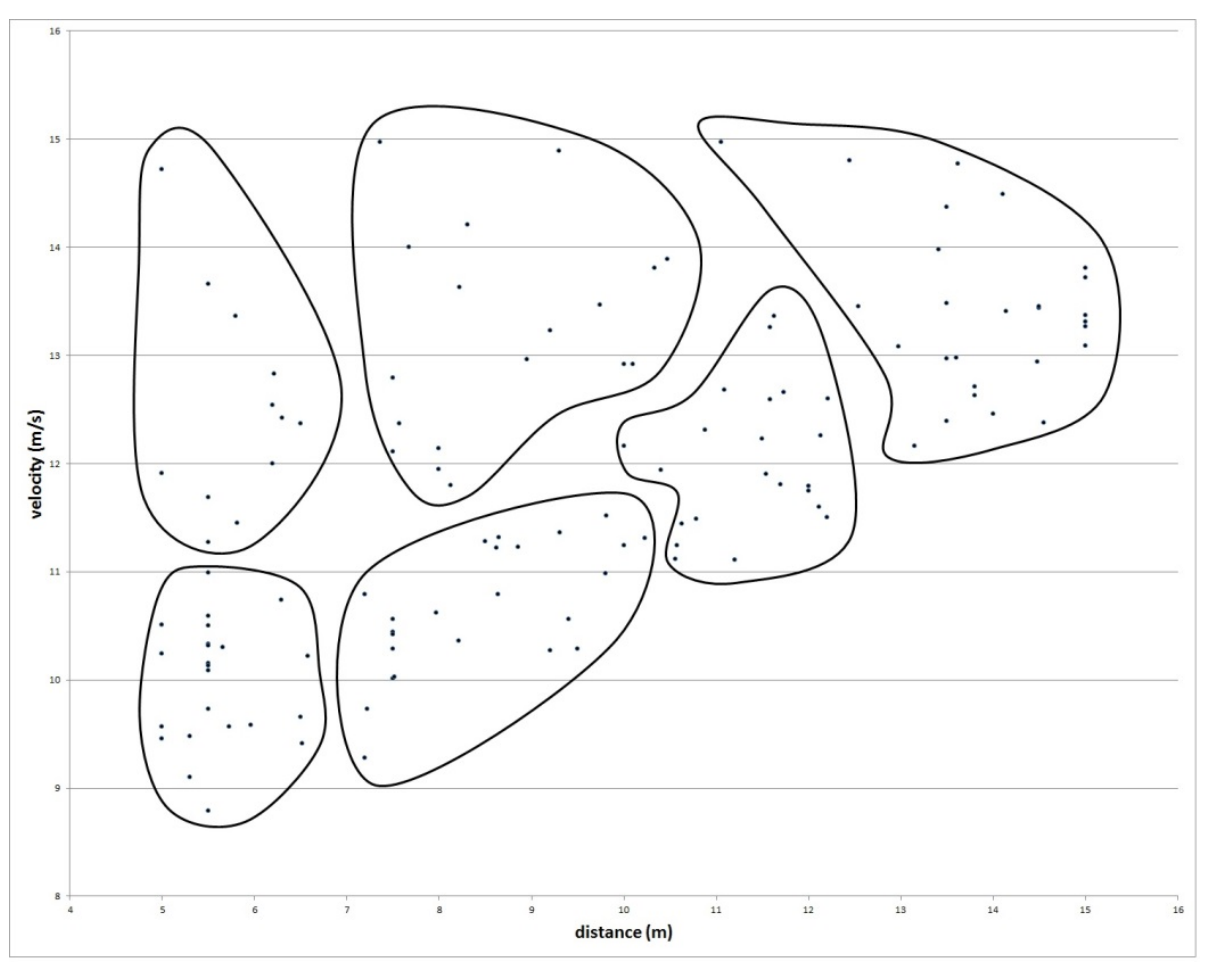

Figure 2. Clusters of lineout throws $(n=126)$ identified according to velocity and distance

Differences among clusters in the different variables examined were detected by ANOVA (see Table 3).

Table 3. Descriptive data for each cluster (mean \pm standard deviation, $95 \%$ confidence interval and Tuckey group in the case of a significant difference) and ANOVA results.

\begin{tabular}{|c|c|c|c|c|c|c|c|}
\hline & $\begin{array}{c}\text { s-f } \\
(n=13)\end{array}$ & $\begin{array}{c}\text { s-sl } \\
(n=22)\end{array}$ & $\begin{array}{c}\text { ms-f } \\
(n=18)\end{array}$ & $\begin{array}{c}\text { ms-sl } \\
(n=24)\end{array}$ & $\begin{array}{c}\mathrm{ml} \\
(\mathrm{n}=22)\end{array}$ & $\begin{array}{c}1 \\
(n=27)\end{array}$ & ANOVA \\
\hline \multirow[t]{3}{*}{ d (m) } & $5.77 \pm 0.49$ & $5.61 \pm 0.49$ & $8.69 \pm 1.08$ & $8.47 \pm 1.00$ & $11.37 \pm 0.66$ & $13.88 \pm 0.95$ & $\mathrm{~F}=$ \\
\hline & $5.31-6.23$ & $5.26-5.96$ & $8.30-9.08$ & $8.14-8.81$ & $11.02-11.72$ & $13.56-14.20$ & 329.79 \\
\hline & Low & Low & $\begin{array}{c}\text { Medium- } \\
\text { low } \\
\end{array}$ & Medium-low & $\begin{array}{l}\text { Medium- } \\
\text { high }\end{array}$ & High & $\begin{array}{l}\mathrm{P}<0.001 \\
\eta^{2}=0.932\end{array}$ \\
\hline \multirow[t]{2}{*}{ h (m) } & $3.43 \pm 0.35$ & $3.63 \pm 0.30$ & $3.66 \pm 0.25$ & $3.70 \pm 0.29$ & $3.68 \pm 0.27$ & $3.49 \pm 0.36$ & $\mathrm{~F}=2.53$ \\
\hline & $3.26-3.60$ & $3.50-3.76$ & $3.52-3.80$ & $3.58-3.82$ & $3.55-3.81$ & $3.37-3.60$ & $\begin{array}{l}P=0.032 \\
\eta^{2}=0.096\end{array}$ \\
\hline \multirow[t]{3}{*}{$t(s)$} & $0.52 \pm 0.06$ & $0.69 \pm 0.09$ & $0.73 \pm 0.10$ & $1.04 \pm 0.18$ & $1.21 \pm 0.15$ & $1.27 \pm 0.18$ & $F=89.57$ \\
\hline & $0.44-0.59$ & $0.63-0.75$ & $0.67-0.80$ & $0.98-1.10$ & $1.15-1.27$ & $1.21-1.32$ & $\mathrm{P}<0.001$ \\
\hline & Low & Medium-low & $\begin{array}{l}\text { Medium- } \\
\text { low }\end{array}$ & $\begin{array}{l}\text { Medium- } \\
\text { high }\end{array}$ & High & High & $\eta^{2}=0.789$ \\
\hline \multirow[t]{3}{*}{$\boldsymbol{\theta}\left({ }^{\circ}\right)$} & $24.15 \pm 4.08$ & $34.11 \pm 4.59$ & $25.54 \pm 2.85$ & $38.73 \pm 6.50$ & $37.64 \pm 5.77$ & $33.68 \pm 5.66$ & $F=79.13$ \\
\hline & $21.28-27.03$ & $31.91-36.32$ & $23.10-27.98$ & $36.61-40.84$ & $35.43-39.85$ & $31.68-35.67$ & $\mathrm{P}<0.001$ \\
\hline & Low & $\begin{array}{c}\text { Medium- } \\
\text { high }\end{array}$ & Low & High & $\begin{array}{c}\text { Medium- } \\
\text { high }\end{array}$ & $\begin{array}{c}\text { Medium- } \\
\text { low }\end{array}$ & $\eta^{2}=0.502$ \\
\hline \multirow[t]{3}{*}{$v\left(m \cdot \mathbf{s}^{-1}\right)$} & $12.40 \pm 1.05$ & $9.93 \pm 0.52$ & $13.23 \pm 0.96$ & $10.66 \pm 0.58$ & $12.04 \pm 0.64$ & $13.40 \pm 0.77$ & $\mathrm{~F}=24.18$ \\
\hline & $11.99-12.81$ & $9.62-10.24$ & $12.88-13.57$ & $10.36-10.96$ & $11.72-12.35$ & $13.12-13.69$ & $\mathrm{P}<0.001$ \\
\hline & $\begin{array}{c}\text { Medium- } \\
\text { high }\end{array}$ & Low & High & Medium-low & $\begin{array}{c}\text { Medium- } \\
\text { high }\end{array}$ & High & $\eta^{2}=0.767$ \\
\hline \multirow[t]{3}{*}{ jp } & $2.08 \pm 0.28$ & $2.36 \pm 0.58$ & $3.17 \pm 1.04$ & $3.50 \pm 0.89$ & $4.50 \pm 1.06$ & $5.26 \pm 0.90$ & $\mathrm{~F}=42.82$ \\
\hline & $1.60-2.55$ & $2.00-2.73$ & $2.76-3.57$ & $3.15-3.85$ & $4.14-4.86$ & $4.93-5.59$ & $\mathrm{P}<0.001$ \\
\hline & Low & Low & Medium & Medium & High & High & $\eta^{2}=0.641$ \\
\hline
\end{tabular}

Abbreviations: $\mathrm{s}-\mathrm{f}=$ short-fast; $\mathrm{s}-\mathrm{sl}=$ short-slow; $\mathrm{ms}-\mathrm{f}=$ medium short-fast; $\mathrm{ml}=$ medium long; $\mathrm{l}=$ long; $\mathrm{d}=$ throw distance; $\mathrm{h}=$ height; $\mathrm{t}=$ flight time; $\Theta=$ starting angle; $\mathrm{v}=$ initial velocity; $\mathrm{jp}=$ jumper position 
Martín, I.; Mira, P.; Salinas, J. S.; Vaz, L., \& Carreras, D. (2018). Kinematic analysis of rugby lineout throws in the Six Nations Tournament. RICYDE. Revista internacional de ciencias del deporte, 52(14), 124-135.

https://doi.org/10.5232/ricyde2018.05203

Through Bonferroni comparisons, differences among the six groups were observed in the variable distance $(\mathrm{P}<0.0001)$ with the exception of short-fast versus short-slow and medium short-fast versus medium short-slow. No significant differences in height were detected in paired comparisons of the six groups. Flight times failed to vary for short-slow versus medium short-fast and medium long versus long. For the variable angle, no differences emerged for the fast type throws (short-fast versus medium short-fast), and neither were differences smaller than $1 \%$ detected for the remaining pairs (short-slow versus medium short-slow and medium long versus long). However, differences did emerge between medium long and long throws $(\mathrm{P}=0.012)$. For the variable initial throw velocity, we detected significant differences at $\mathrm{P}<0.01$ among all the throw types except medium long versus long and short-slow versus medium long $(\mathrm{P}<0.05)$ yet no significant differences were observed between short-fast and short-slow or between medium long and long throws $(\mathrm{P}>0.99)$. Finally, for lineout jumper position, no differences at $1 \%$ were recorded in the comparisons short-fast versus short-slow, medium short-fast versus medium short-slow and short-slow versus medium short-fast, and at $5 \%$ in medium long versus long $(\mathrm{P}=0.04)$ and short-fast versus medium short-fast $(\mathrm{P}=0.011)$.

Taking into account all this information along with the groupings provided by the Tuckey comparisons we were able to characterize each type of throw as a function of the variables examined to make the differences identified between the throws easier to understand (see Table 3).

To examine the contribution of each variable to the capacity to predict each of the six clusters used as the criterion variable, we conducted a discriminant analysis entering as the qualitative dependent variable the six classification groups obtained in the cluster analysis and as independent variables distance, height, flight time, angle, velocity and jumper position. Given the number of independent variables, we selected the stepwise procedure and Mahalanobis $\mathrm{D}^{2}$ measurement method. After stepwise analysis, the variables velocity, distance, flight time, angle and height were included in this order. Jumper position was finally excluded from the model. Results indicated $\lambda=0.012, \mathrm{P}<0.0001$ for function $1, \lambda=0.183, \mathrm{P}<0.0001$ for function $2, \lambda=0.546, \mathrm{P}<0.0001$ for function 3 and $\lambda=0.922, \mathrm{P}=0.045$ for function 4 . Function 5 was not significant $(\lambda=1.00 ; \mathrm{P}=0.897)$ and thus excluded. The percentage of variance explained for each of the four functions were $84.3,11.3,3.9$ and 0.5 respectively adding up to $100 \%$. Finally, the analysis revealed that $100 \%$ of the throws were correctly classified.

\section{Differences by team}

Each of the six participating teams, or nations, could be differentiated according to the variables examined by ANOVA (see Table 4). 
Martín, I.; Mira, P.; Salinas, J. S.; Vaz, L., \& Carreras, D. (2018). Kinematic analysis of rugby lineout throws in the Six Nations Tournament. RICYDE. Revista internacional de ciencias del deporte, 52(14), 124-135. https://doi.org/10.5232/ricyde2018.05203

Table 4. Descriptive data for each team (mean \pm standard deviation, 95\% confidence interval and Tuckey group in the case of a significant difference) and ANOVA results.

\begin{tabular}{|c|c|c|c|c|c|c|c|}
\hline & $\begin{array}{c}\text { IT } \\
(n=11)\end{array}$ & $\begin{array}{c}\text { ENG } \\
(n=27)\end{array}$ & $\begin{array}{c}\text { IRE } \\
(n=21)\end{array}$ & $\begin{array}{c}\text { SCO } \\
(n=15)\end{array}$ & $\begin{array}{c}\text { FRA } \\
(n=20)\end{array}$ & $\begin{array}{c}\text { WALES } \\
(\mathrm{n}=\mathbf{3 2})\end{array}$ & ANOVA \\
\hline \multirow[t]{2}{*}{ d (m) } & $11.15 \pm 3.60$ & $9.48 \pm 3.07$ & $8.84 \pm 3.18$ & $9.26 \pm 3.54$ & $9.73 \pm 2.73$ & $8.91 \pm 3.02$ & \multirow{2}{*}{$\begin{array}{c}F=1.04 \\
P=0.409 \\
\eta^{2}=0.041\end{array}$} \\
\hline & $9.28-13.02$ & $8.28-10.67$ & $7.49-10.19$ & $7.67-10.87$ & $8.35-11.12$ & $7.81-10.00$ & \\
\hline \multirow[t]{3}{*}{$h(m)$} & $3.64 \pm 0.37$ & $3.53 \pm 0.29$ & $3.49 \pm 0.36$ & $3.85 \pm 0.24$ & $3.48 \pm 0.21$ & $3.68 \pm 0.30$ & \multirow{3}{*}{$\begin{array}{l}F=4.05 \\
P=0.002 \\
\eta^{2}=0.144\end{array}$} \\
\hline & $3.47-3.82$ & $3.42-3.65$ & $3.36-3.62$ & $3.70-4.00$ & $3.35-3.62$ & $3.58-3.79$ & \\
\hline & Medium & Low & Low & High & Low & Medium & \\
\hline \multirow[t]{3}{*}{$t(s)$} & $1.22 \pm 0.32$ & $0.88 \pm 0.29$ & $0.87 \pm 0.23$ & $1.02 \pm 0.32$ & $1.01 \pm 0.29$ & $0.93 \pm 0.31$ & \multirow{3}{*}{$\begin{array}{c}\mathrm{F}=2.85 \\
\mathrm{P}=0.018 \\
\eta^{2}=0.106\end{array}$} \\
\hline & $1.05-1.40$ & $0.77-0.99$ & $0.74-0.99$ & $0.87-1.17$ & $0.88-1.14$ & $0.83-1.04$ & \\
\hline & High & Low & Low & Medium & Medium & Low & \\
\hline \multirow[t]{3}{*}{$\theta\left({ }^{\circ}\right)$} & $39.10 \pm 6.33$ & $29.38 \pm 5.67$ & $30.61 \pm 5.59$ & $37.65 \pm 6.15$ & $33.56 \pm 8.12$ & $34.03 \pm 7.43$ & \multirow{3}{*}{$\begin{array}{c}F=5.55 \\
P<0.001 \\
\eta^{2}=0.188\end{array}$} \\
\hline & $35.11-43.09$ & $26.84-31.93$ & $27.72-33.50$ & $34.24-41.07$ & $30.60-36.52$ & $31.69-36.37$ & \\
\hline & High & Low & Low & High & Medium & Medium & \\
\hline \multirow[t]{2}{*}{$v\left(m \cdot s^{-1}\right)$} & $11.70 \pm 1.47$ & $12.53 \pm 1.11$ & $11.73 \pm 1.68$ & $11.48 \pm 1.34$ & $11.85 \pm 1.55$ & $11.81 \pm 1.70$ & \multirow{2}{*}{$\begin{array}{c}\mathrm{F}=1.30 \\
\mathrm{P}=0.270 \\
\eta^{2}=0.051\end{array}$} \\
\hline & $10.80-12.59$ & $11.95-13.10$ & $11.08-12.38$ & $10.71-12.25$ & $11.19-12.52$ & $11.29-12.34$ & \\
\hline \multirow[t]{2}{*}{ jp } & $4.27 \pm 1.62$ & $3.70 \pm 1.59$ & $3.38 \pm 1.40$ & $3.33 \pm 1.35$ & $3.90 \pm 1.07$ & $3.59 \pm 1.41$ & \multirow{2}{*}{$\begin{array}{r}F=0.87 \\
P=0.502 \\
\eta^{2}=0.035\end{array}$} \\
\hline & $3.43-5.12$ & $3.17-4.24$ & $2.77-3.99$ & $2.61-4.06$ & $3.27-4.53$ & $3.10-4.09$ & \\
\hline
\end{tabular}

Abbreviations: $d=$ throw distance; $h=$ height; $\mathrm{t}=$ flight time; $\Theta=$ starting angle; $\mathrm{v}=$ initial velocity; $\mathrm{jp}=$ jumper position

According to Bonferroni comparisons, the variable height could significantly differentiate Scotland from France (difference means $\mathrm{d}=0.37 \mathrm{~m} \mathrm{P}=0.008)$, Ireland $(\mathrm{d}=0.36 \mathrm{~m} \mathrm{P}=0.009)$ and England $(\mathrm{d}=0.32 \mathrm{~m} P=0.022)$, time of flight served to distinguish Italy from Ireland $\mathrm{d}=0.33 \mathrm{~s}$ and England $\mathrm{d}=0.34 \mathrm{~s}$ (both $\mathrm{P}=0.023$ ), while throw angle differentiated between Ireland versus Scotland $\left(\mathrm{d}=7.04^{\circ} \mathrm{P}=0.034\right)$ or Italy $\left(\mathrm{d}=8.49^{\circ} \mathrm{P}=0.013\right)$ and between England also versus Scotland $\left(\mathrm{d}=8.27^{\circ} \mathrm{P}=0.003\right)$ or Italy $\left(\mathrm{d}=9.72^{\circ} \mathrm{P}<0.001\right)$.

As for the lineout throw types, we were able to characterize each variable in each team according to the groupings emerging from the Tuckey comparisons (see Table 4).

\section{Discussion}

Through a descriptive study and cluster analysis, we were able to classify a set of lineout throws into six different types defined in terms of four distances from the thrower to the jumper capturing the ball (short, medium short, medium long and long) and two subdivisions into fast and slow of the two former types according to throw velocity. Each of these throw types could also be characterized as having ball throwout angles, flight times and possession gained by players in different lineout positions. The height at which possession is won merits further attention. Thus, despite overall differences in this variable detected by ANOVA of under 5\% no differences were observed when comparisons were pairwise. It therefore seems that lineouts were won at the same height regardless of throw type. At most, we could say that all lineouts were conquered at the same height, though with a tendency of short-fast and long throws to be won at lower heights. This finding is relevant given that, independently of ball velocity and trajectory, the height of possession is the same. This means that despite the straight or curved trajectory of a throw, it may be won at more or less the same height. According to the data obtained on ball initial velocity and throw angle, it is possible to approximately calculate, through simulation based on parabolic throws, the ball trajectory for each of the six throw classes (see Figure 2). 
Martín, I.; Mira, P.; Salinas, J. S.; Vaz, L., \& Carreras, D. (2018). Kinematic analysis of rugby lineout throws in the Six Nations Tournament. RICYDE. Revista internacional de ciencias del deporte, 52(14), 124-135. https://doi.org/10.5232/ricyde2018.05203

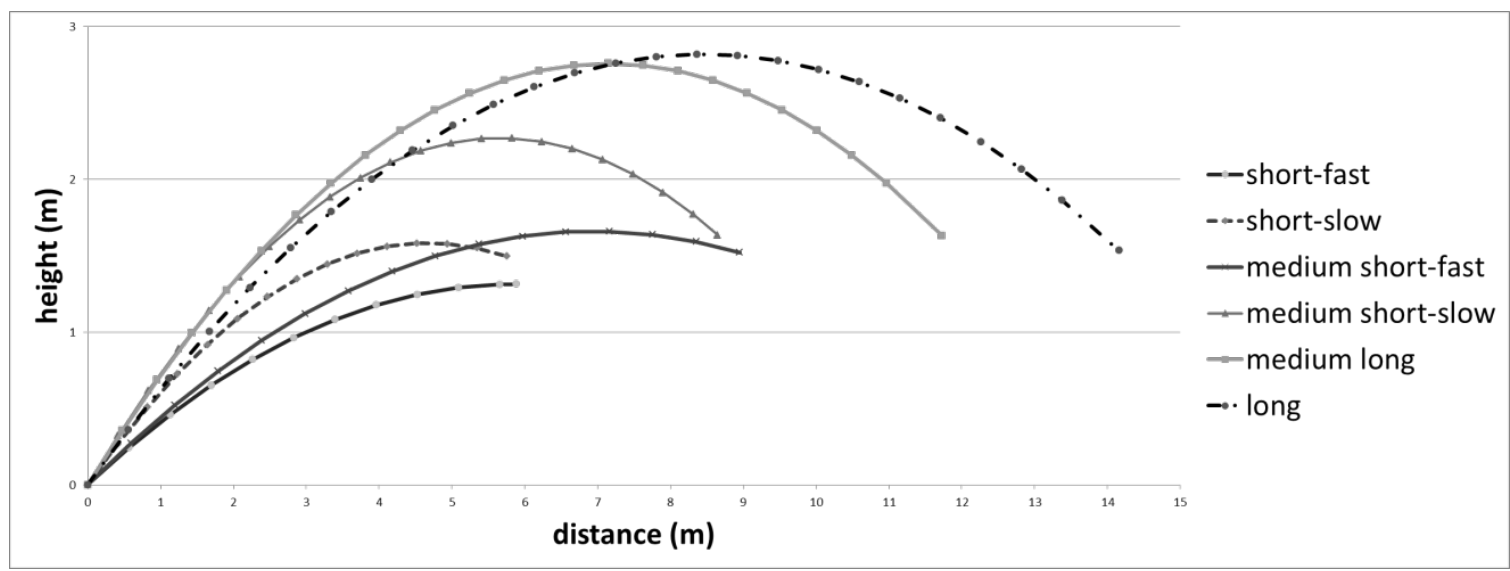

Figure 3. Trajectories calculated using parabolic throw equations for each of the six types of throw identified according to velocity and angle. Trajectories are represented as the point from which the ball leaves the thrower's hands to the point at which the player in the lineout gains possession of the ball.

It is difficult to compare our data with the results of other studies due to the different data collection methods. There are no prior reports of kinematic data obtained in real game play situations. As mentioned earlier, most published data were generated in controlled settings, mostly indoor or laboratory, and the final objective of such studies has been a biomechanical analysis of the thrower.

We can, nevertheless, compare our data with those derived from these investigations. In all prior studies, throw distances were fixed. These were 6,10 and $15 \mathrm{~m}$ in the trials of Croft et al. (2011) and Sayers $(2004,2011)$ and 5, 10 and $15 \mathrm{~m}$ in that of Griffiths and Hughes (2005). Trewartha, Casanova, and Wilson (2008) tested four distances 6, 10, 12 and $14 \mathrm{~m}$ consistent with the number emerging from the present study. However, these authors defined seven types of throw (four distances with subdivisions straight and curved of the first three) compared to our six types.

With regards to ball possession height, Trewartha et al. (2008) tested a fixed height of $3.25 \mathrm{~m}$ while in the study by Sayers (2011), the throw was targeted at a jumper elevated by two players, but these authors provided no data on possession height. We detected an appreciably greater height of 3.43 and $3.70 \mathrm{~m}$ for all throw types.

Only Trewartha et al. (2008) have provided data on the angle at which the ball is thrown. The figures reported by these authors for straight throws and curved throws respectively were 25 to $28^{\circ}$ and 43 to $45^{\circ}$ at $6 \mathrm{~m} ; 27$ to $36^{\circ}$ and 40 to $44^{\circ}$ at $10 \mathrm{~m} ; 28$ to $32.5^{\circ}$ and 40 to $44^{\circ}$ at $12 \mathrm{~m}$; and 35 to $37^{\circ}$ at $14 \mathrm{~m}$. Our figures (see Table 3) were a couple of degrees higher for most distances, though greater differences were observed between flat and slow throws, especially between short-slow and curved throws at $6 \mathrm{~m}$. Besides the varying data collection methods, this difference may be attributed to the fact that these authors classified the throws by distance and angle, whereas we used distance and velocity to differentiate our throws. In addition, Trewartha et al. (2008) examined three throwers with different skill levels while the present throwers were all international competition level players.

The velocities obtained by Trewartha et al. (2008) were: 10.5 to $11.5 \mathrm{~m} \cdot \mathrm{s}^{-1}$ in straight throws and 8 to $9 \mathrm{~m} \cdot \mathrm{s}^{-1}$ in curved throws at $6 \mathrm{~m}$; and 11 to $12.5 \mathrm{~m} \cdot \mathrm{s}^{-1}$ and 10 to $10.5 \mathrm{~m} \cdot \mathrm{s}^{-1}$ respectively at $10 \mathrm{~m} ; 12$ to $12.5 \mathrm{~m} \cdot \mathrm{s}^{-1}$ and 11 to $12 \mathrm{~m} \cdot \mathrm{s}^{-1}$ at $12 \mathrm{~m}$; and 12 to $13 \mathrm{~m} \cdot \mathrm{s}^{-1}$ at $14 \mathrm{~m}$. Sayers (2011) obtained velocities of $8.31,9.31$ and $10.36 \mathrm{~m} \cdot \mathrm{s}^{-1}$ for his three distances respectively, that is, $10 \%$ lower than the latter authors, and attributed these differences to variations produced when launching a static object from a fixed height compared to throwing 
Martín, I.; Mira, P.; Salinas, J. S.; Vaz, L., \& Carreras, D. (2018). Kinematic analysis of rugby lineout throws in the Six Nations Tournament. RICYDE. Revista internacional de ciencias del deporte, 52(14), 124-135.

https://doi.org/10.5232/ricyde2018.05203

to a jumper helped by two team mates as in his case. Sayers' (2011) data was also derived from three international rugby players compared to the subjects of more varying level included in the study by Trewartha et al. (2008). Our velocity data are more consistent though considerably higher than those of Trewartha et al. (2008) and thus also higher than the velocities provided by Sayers (2011). It should be, nevertheless, noted that the velocities recorded in the present study are consistent with prior data and any differences could be explained by the data collection methods.

A second objective of our study was to differentiate between the teams participating in the tournament. According to team, we detected significant differences in three variables: throw height, flight time and angle. Thus, Scotland wins its lineouts at significantly higher heights than England, Ireland and France. Flight times for Italy are longer than for England and Ireland. Finally, Scotland and Italy throw the ball at a wider angle than England and Ireland.

\section{Conclusions}

The present data have implications for training and game analysis. Hence, a coach could design a training programme or check a given training protocol based on data obtained in real game play and could therefore optimize tasks for a given objective. In addition, the coach will gain an exhaustive understanding of the game tactics of opponents and accordingly will be able to plan strategies to overcome these actions. For example, lineout histories could be mapped for each team (including the distances and heights of all lineouts taken) and thus, the most likely distance and height of capturing the ball could be determined for a given team.

We also feel that these data will provide direction for future investigations. Such studies will enable us to know the types and characteristics of international-level lineouts and, for example, if we wish to obtain biomechanical data, we could use four jumper positions and different angles for two of these positions. This could help in deciding which height possession could be won.

As limitations to our study, we could not analyze every lineout taken, given that the video footage rather than ex profeso was obtained from televised matches. Also some degree of error could be attributed to the use of parabolic equations for the throws, which fail to account for friction or different conditions such as weather.

\section{References}

Charrad, M.; Ghazzali, N.; Boiteau, V.; Niknafs, A., \& Charrad, M. M. (2014). Package NbClust: an R package for determining the relevant number of clusters in a data set. Journal of Statistical Software, 61(6), 1-36. https://doi.org/10.18637/jss.v061.i06

Croft, H.; Chong, A., \& Wilson, B. (2011). Virtual reality assessment of rugby lineout throw kinematics. Sports Technology, 4(1-2), 2-12. https://doi.org/10.1080/19346182.2012.663535

Griffiths, I.W., \& Hughes, G. (2005). Kinematic analysis of rugby union lineout Throw. (Abstract). Journal of Sports Sciences, 23(2), 102-103.

Hair, J. F.; Anderson, R. E.; Tatham, R. L., \& Black, W. C. (1999). Análisis Multivariante (5 $5^{a}$ ed.). Madrid: Prentice-Hall Iberia.

Haynes, S. N.; Richard, D. C. S., \& Kubany, E.S. (1995). Content validity in psychological assessment: A functional approach to concepts and methods. Psyhological Assessment, 7(3), 238-247.

IBM Corp. (2012). IBM SPSS Statistics for Windows, Version 21.0. Armonk, NY: IBM Corp. 
Martín, I.; Mira, P.; Salinas, J. S.; Vaz, L., \& Carreras, D. (2018). Kinematic analysis of rugby lineout throws in the Six Nations Tournament. RICYDE. Revista internacional de ciencias del deporte, 52(14), 124-135.

https://doi.org/10.5232/ricyde2018.05203

International Rugby Board (2013a). Statistical analysis and match review, Six nations 2013. Retrieved 5 May 2014 from:

http://www.irb.com/mm/document/newsmedia/mediazone/02/06/63/

56/130325sixnations2013statisticalreport.pdf

International Rugby Board (2013b) Leyes del juego 2013. Retrieved 5 May 2014 from: http://www.rugby.nl/sites/default/files/bestanden/IRB_Laws_2013_EN_0.pdf

Jones, N. M. P.; Mellalieu, S. D., \& and James, N. (2004). Team performance indicators as a function of winning and losing in rugby union. International Journal of Performance Analysis in Sports, 4(1), 61-71.

Lipscombe T. D. (2009). The physics of rugby. Nottingham: Nottingham University Press,

Martín, I.; Olmo, J.; Chirosa, L. J.; Carreras, D., \& Solá, J. (2013). Bibliometric study (1922-2009) on rugby articles in research journals. South African Journal for Research in Sport, Physical Education and Recreation, 35(1), 105-119.

Microsoft Corp. (2010). Microsoft Excel. Redmond, WA: Microsoft Corp.

Ortega, E.; Villarejo, D., \& Palao, J. M. (2009). Differences in game statistics between winning and losing rugby teams in the Six Nations Tournament. Journal of Sports Science and Medicine, 8, 523-527.

Sayers, M. (2004). A three-dimensional analysis of lineout throwing in rugby union, Journal of Sports Sciences, 22, 498-499.

Sayers, M. (2011). Kinematic analysis of line-out throwing in elite international rugby union. Journal of Sports Science and Medicine, 10, 553-558.

Trewartha, G.; Casanova, R.; \& Wilson, C. (2008). A kinematic analysis of rugby lineout throwing. Journal of Sports Sciences, 26(8), 845-854. https://doi.org/10.1080/02640410701885629

Vaz, L.; Van Rooyen, M., \& Sampaio, J. (2010). Rugby game-related statistics that discriminate between winning and losing teams in IRB and Supertwelve close games. Journal of Sports Science and Medicine, 9, 51-55.

Villarejo, D.; Palao, J. M., \& Ortega, E. (2010). Scientific production in Rugby union between 1998-2007. Revista de Ciencias del Deporte, 6(3), 155-161. 